\title{
The studies of metal-bearing nanoparticles from the concealed deposits and their prospecting significance
}

\author{
BIMIN ZHANG ${ }^{1,2, *}$ XUEQIU WANG ${ }^{1,2}$
}

${ }^{1}$ Institute of Geophysical and Geochemical Exploration, CAGS, Langfang, 065000, China

${ }^{2}$ Key Laboratory for Geochemical Exploration Technology, MNR, Langfang, 065000, China

(*correspondence: zolozhbm@163.com)

Geochemists conjectured that ultrafine metal-bearing particles could be carried onto bubbles or micro-flow of geogas and migrates upward to the surface[1]. After years of study, nano-scale metal-bearing particles have been widely observed in geogas samples from different kinds of concealed deposits. However, no direct evidence has been observed to demonstrate the occurrences and formation of the metals.

To investigate it, metal-bearing nanoparticles were observed in geogas, soil, water, fault gouge and ore samples collected from concealed ore deposits by using transmission electron microscope (TEM). The observation results showed that 1) nanoparticles of native metals, alloys or crystals widely occur in different kinds of samples in the mineral deposits; 2) the particles tend to agglomerate into clustering forms; 3) the most obvious difference among nanoparticles collected from different types of deposits is the chemical compositions that nanoparticles at $\mathrm{Au}$ and $\mathrm{Ag}$-polymetallic deposits have $\mathrm{Au}$ element, while nanoparticles at $\mathrm{Cu}-\mathrm{Ni}$ deposit have $\mathrm{Ni}$ and $\mathrm{Cr}$ elements; 4) the metal-bearing nanoparticles tend to be adsorbed on the surface of clay minerals, 5) nanoscale metal particles are not discovered in the samples collected from the background zone.

The results indicate that nanoparticles of metals have good inheritance relationships with the deposits. The oreforming elements in geogas and soils can only come from deep-seated ore bodies and they occur in nanoparticles in the study area. The discovery of nanoscale particles in geogas, soil and water over concealed ore bodies provides direct observation evidence for deep-penetrating geochemistry using these meterials as sampling media to search for deeply concealed ore deposits and also gives us an enlightenment to seek a new geochemical method through microscopic observation for mineral exploration in covered area.

This work is financed by the State Key Research \& Development Project (2016YFC0600602) and National Natural Science Foundation of China (41573044).

[1] Kristiansson et al (1982). Geophysics, 47, 1444-1452. 